Izumi, Volume 7 No 2, 2018

e-ISSN: 2502-3535, p-ISSN: 2338-249X

Tersedia online di http://ejournal.undip.ac.id/index.php/izumi

\title{
DEUS VERSUS OHIRUME DALAM CERPEN KAMIGAMI NO BISHOU: BENTURAN BUDAYA ANTARA BARAT DENGAN JEPANG
}

\author{
Zaki Ainul Fadli \\ Fakultas Ilmu Budaya, Universitas Diponegoro \\ zakiaf@live.undip.ac.id
}

\begin{abstract}
Abstrak
Cerpen Kamigami no Bishou adalah salah satu karya sastrawan Jepang yang termasyhur yaitu Akutagawa Ryuunosuke. Kamigami no Bishou dipublikasikan pada tahun 1922 yang menceritakan pertemuan Organtino, seorang misionaris Kristen di Jepang dengan seorang lelaki tua yang merupakan perwujudan dari salah satu dewa kuno Jepang. Tujuan penulisan artikel ini adalah untuk mengungkap bagaimana benturan budaya antara Barat dengan Jepang direkonstruksikan dalam cerpen Kamigami no Bishou. Untuk mencapai tujuan tersebut dilakukan langkah-langkah berikut. Pertama, dijelaskan istilah-istilah yang terdapat dalam Cerpen Kamigami no Bishou. Kedua, dijelaskan tindakan dua tokoh di dalam cerpen yang saling beroposisi dengan skema aktansial model Greimas karena skema ini dapat mempermudah dalam memahami tindakan dan motivasi tokoh. Ketiga, analisis salah satu elemen struktur cerpen yaitu tema dengan tujuan untuk memahami inti dan maksud dari keseluruhan isi cerpen. Keempat, pemaparan lebih lanjut mengenai rekonstruksi benturan budaya Barat versus Jepang yang dijelaskan dengan pemaparan oposisi biner. Setelah melalui keempat tahap tersebut didapatkan kesimpulan bahwa rekonstruksi benturan budaya dalam cerpen Kamigami no Bishou dipaparkan oleh Akutagawa melalui percakapan antara tokoh Organtino dengan tokoh lelaki tua. Melalui dialog yang berpusat pada Deus versus Ohirume yang dilakukan oleh tokoh Organtino dan tokoh lelaki tua, secara tidak langsung Akutagawa ingin menyampaikan pesan bahwa tradisi dan budaya Jepang tidak akan hancur karena pengaruh dari budaya asing yang masuk.
\end{abstract}

Kata kunci: Kamigami no Bishou; oposisi biner; benturan budaya

\begin{abstract}
(Title: Deus Versus Ohirume in Kamigami no Bishou: Cultural Clash Between West and Japan) The Kamigami no Bishou short story is one of the most famous Japanese literary works, Akutagawa Ryunnosuke. Kamigami no Bishou was created by Akutagawa in 1922 which tells the meeting of Organtino, a Christian missionary in Japan with an old man who was the embodiment of one of Japan's ancient gods. The purpose of this article is to reveal how the clash of cultures between the West and Japan was reconstructed in Kamigami no Bishou short stories. To achieve this goal, the following steps are taken. First, an explanation of the terms contained in the Kamigami no Bishou Short Story. Second, explained the actions of two figures in the short story that are in opposition to the Greimas model's official scheme because this scheme can make it easier to understand the actions and motivations of the characters. Third, the analysis of one of the short story structural elements is a theme with the aim of understanding the essence and purpose of the entire short story. Fourth, further
\end{abstract}


explanation about the reconstruction of Western versus Japanese cultural clash which is explained by the presentation of binary opposition. After going through all four stages, it was concluded that the reconstruction of cultural clash in Kamigami no Bishou short stories was presented by Akutagawa in a conversation between the Organtino character and the old male character. Through a dialogue centered on Deus versus Ohirume carried out by Organtino figures and old male figures, Akutagawa indirectly wanted to convey the message that Japanese tradition and culture would not be destroyed due to influences from foreign cultures that entered.

Keywords: Kamigami no Bishou; binary opposition; cultural clash

\section{Pendahuluan}

Karya sastra diciptakan sastrawan untuk mengekspresikan ide, gagasan, atau pemikiran mengenai kehidupan. Terkadang ide, gagasan, atau pemikiran yang termuat dalam karya sastra tersebut merupakan wacana yang dituliskan tidak dalam kalimatkalimat yang eksplisit, tetapi dilukiskan dalam sesuatu yang implisit. Penggunaan gaya bahasa dan diksi dan penataan alur berperan penting sebagai alat bagi sastrawanuntuk menciptakan keindahan dalam karya sastra.

Cerpen Kamigami no Bishou adalah salah satu karya sastrawan Jepang yang termasyhur yaitu Akutagawa Ryuunosuke. Kamigami no Bishou diciptakan Akutagawa pada tahun 1922 yang diterbitkan di Majalah Shinshosetsu『新小説』 (https://ja.wikipedia.org/wiki/神神の微笑). Cerpen Kamigami no Bishou menyajikan wawasan budaya Jepang dan filosofi mengenai kekristenan seperti novel Chinmoku karya Shushaku Endo (Gessel, 2018).

Cerpen ini menceritakan pertemuan Organtino, seorang misionaris Kristen di Jepang dengan seorang lelaki tua yang merupakan perwujudan dari Ohirume, dewa kuno Jepang. Dalam dialog antara keduanya, diketahui bahwa Organtino adalah sosok misionaris yang mempunyai tekad kuat untuk mengkristenkan Jepang, sedangkan lelaki tua itu muncul dihadapan Organtino untuk memperingatkan bahwa usaha Organtino tersebut akan berakhir sia-sia di tanah Jepang. Menurut lelaki tua tersebut, ajaran dari luar termasuk Kristen tidak akan berkembang dengan baik karena Jepang telah terbukti mempunyai kemampuan untuk menerima ajaran atau pengaruh dari luar tetapi tidak akan diserap dengan begitu saja. Pengaruh dari luar tersebut akan ditransformasikan ke dalam bentuk yang khas Jepang sehingga hasilnya terbentuk sinkretisme ${ }^{1}$ yang khas diwarnai oleh budaya asli Jepang. Masih menurut lelaki tua itu, dengan kata lain, Deus (Tuhan dalam Bahasa Latin) akan kalah dengan Ohirume (dewa kuno Jepang).

Tokoh Organtino dalam cerpen diindikasikan merujuk pada Soldo Organtino, seorang misionaris Kristen di Jepang. Berdasarkan tulisan Cieslik (2005), Soldo Organtino lahir di Italia pada 1533, memulai misinya di Jepang pada 18 Juni 1570 , dan meninggal di Nagasaki, Jepang pada 22 April 1609.

Menurut Essertier (2014), cerpen ini luput dari pengamatan kritikus sastra Jepang. Masih di tulisan Essertier, menurut Shusaku Endo, hanya Jun'ichiro Sako satu-satunya pengamat yang menekankan pentingnya cerpen ini di antara cerpen Akutagawa lainnya. Essertier mengatakan bahwa terdapat dialog intelektual dalam cerpen ini. Dialog intelektual yang dimaksud adalah dialog antara Organtino yang merepresentasikan budaya Barat dan lelaki

\footnotetext{
${ }^{1}$ Sinkretisme adalah suatu proses perpaduan dari beberapa pahampaham atau aliran-aliran agama atau kepercayaan.

Pada sinkretisme terjadi proses pencampuradukkan berbagai unsur aliran atau paham, sehingga hasil yang didapat dalam bentuk abstrak yang berbeda untuk mencari keserasian, keseimbangan. (https://id.wikipedia.org/wiki/Sinkretisme)
} 
Izumi, Volume 7 No 2, 2018

e-ISSN: 2502-3535, p-ISSN: 2338-249X

Tersedia online di http://ejournal.undip.ac.id/index.php/izumi

tua yang merepresentasikan Jepang. Hanya saja, tidak dijelaskan lebih jauh bagaimana representasi budaya Barat versus budaya Jepang ini direkonstruksikan dalam cerpen tersebut.

Tulisan lain mengenai cerpen Kamigami no Bishou ditulis oleh Seiji M. Lippit (1999) yang mengatakan bahwa dalam cerpen ini Akutagawa memiliki kekuatan dalam kemampuannya menghasilkan tulisan dialektikal yang mampu menghadapi dominasi budaya Barat. Hal tersebut tersirat di dalam cerpen ketika dewa-dewa Jepang yang bisa dimaknai sebagai politheism² "unggul" atas Organtino yang menganut monotheisme.

Sedangkan pada tulisan Karatani (1991) disebutkan bahwa dalam cerpen Kamigami no Bishou, Akutagawa menuliskan bahwa segala pemikiran dari luar Jepang, baik dari China, India, maupun negara-negara Barat, akan ditransformasi oleh kami atau para dewa Jepang.

Deus, adalah Bahasa Latin yang merujuk pada Yesus, Tuhannya umat Kristen. Adapun Ohirume adalah nama lain dari dewa utama di Jepang yaitu Amaterasu Omikami. Yang menarik dari cerpen ini adalah dua nama tersebut dijadikan sebagai sosok yang dipertentangkan. Deus sangat dipuja oleh Organtino, dijadikan sandaran dan panutan bagi Organtino. Adapun Ohirume dijagokan oleh tokoh lelaki tua akan menang melawan pengaruh ajaran Deus di Jepang.

Masih menurut tokoh lelaki tua itu, Ohirume dan para dewa di Jepang senantiasa menjaga bangsa Jepang dari pengaruh asing yang masuk ke Jepang. Tidak harus dengan melawan dan mengalahkannya, tetapi dengan kekuatan adaptasi dan transformasi akan mengubah pengaruh asing itu ke dalam

${ }^{2}$ Politeisme adalah bentuk kepercayaan yang mengakui adanya lebih dari satu Tuhan. Secara harfiah berasal dari bahasa Yunani poly + theoi, yang berarti banyak tuhan. Lawan dari paham ini adalah monoteisme, atau kepercayaan yang hanya mengakui satu Tuhan. ( https://id.wikipedia.org/wiki/Politeisme) bentuk yang sesuai dengan budaya Jepang, sehingga akan tercipta bentuk baru yang khas Jepang yang berbeda dengan aslinya. Dengan kata lain, Deus versus Ohirume di dalam cerpen ini dijadikan oleh Akutagawa sebagai cara untuk mengungkapkan atau merekonstruksi benturan budaya antara asing vs Jepang.

Berdasarkan hal di atas, terdapat kekuatan Jepang dalam menghadapi pengaruh asing yang ditonjolkan oleh Akutagawa dalam cerpen Kamigami no Bishou. Tujuan penulisan artikel ini adalah untuk mengungkap bagaimana rekonstruksi benturan budaya antara Barat dengan Jepang dalam cerpen Kamigami no Bishou.

\section{Metode}

Untuk mencapai tujuan penelitian, diperlukan kajian struktur untuk menjelaskan konflik antara Organtino yang merupakan representasi Dunia Barat dengan sosok lelaki tua yang merupakan jelmaan dari salah satu Dewa Jepang yang merepresentasikan Jepang. Pertama, penjelasan istilah-istilah yang terdapat dalam Cerpen Kamigami no Bishou. Kedua, dijelaskan tindakan dua tokoh di dalam cerpen yang saling beroposisi dengan skema aktansial model Greimas karena skema ini dapat mempermudah dalam memahami tindakan dan motivasi tokoh. Greimas mengklaim bahwa tiga oposisi biner dasar mendasari semua tema naratif, tindakan dan jenis karakter (yang secara kolektif ia sebut aktan), yaitu: subject-object, sender-receiver dan helper-opponent (Chandler, 2005). Ketiga, analisis salah satu elemen struktur cerpen yaitu tema dengan tujuan untuk memahami inti dan maksud dari keseluruhan isi cerpen. Keempat, pemaparan lebih lanjut mengenai rekonstruksi benturan budaya Barat versus Jepang yang dijelaskan dengan pemaparan oposisi biner

\section{Hasil dan Pembahasan}

Cerpen Kamigami no Bishou berkisah mengenai tokoh Organtino yang resah karena di satu sisi ingin pulang ke negaranya, tetapi di sisi lain dia sangat mengagumi dan 
Izumi, Volume 7 No 2, 2018

e-ISSN: 2502-3535, p-ISSN: 2338-249X

Tersedia online di http://ejournal.undip.ac.id/index.php/izumi

betah dengan keindahan alam Jepang. Organtino percaya ada kekuatan misterius yang menghalanginya untuk melaksanakan misi kristenisasinya di Jepang. Hal itu menyebabkan keinginannya untuk pulang ke menjadi bertambah. Dari awal hingga akhir cerita, tokoh Organtino selalu dimunculkan. Oleh karena itu, Organtino adalah tokoh utama dalam cerpen Kamigami no Bishou. Selain Organtino, tokoh lain yang penting dan dapat disebut tokoh utama adalah tokoh lelaki tua. Walaupun diceritakan dengan porsi lebih sedikit, tetapi tokoh lelaki tua ini memiliki peran yang besar dalam jalannya cerita dan apabila dihilangkan tentu akan mengubah isi cerita.

\subsection{Penjelasan Istilah}

Cerpen Kamigami no Bishou memuat istilah-istilah yang berkaitan dengan agama dan sejarah. Oleh karena itu, beberapa istilah-istilah penting itu perlu untuk dijelaskan terlebih dahulu. Berikut beberapa istilah penting yang terdapat dalam cerpen.

\section{1) Deus}

Deus adalah istilah untuk menyebutYesus (Tuhan umat Kristen).Selama tahap awal misinyadi Jepang, misionaris Katolik Francis Xavier disambut oleh para biarawan Shingon karena dia menggunakan Dainichi, nama Jepang untuk Vairocana, untuk menunjuk Tuhan Kristen. Ketika Xavier belajar lebih banyak tentang nuansa religius dari kata itu, Xavier menjadi paham bahwa ternyata istilah Dainichi sebenarnya digunakan untuk merujuk dewa-dewa polytheis Jepang. Oleh karena itu, Xavier mengganti istilah Dainichi menjadi Deus (泥烏須) untuk menyebut Tuhan Kristen. Deus berasal dari bahasa Latin dan Portugis Deus (https://en.wikipedia.org/wiki/Vairocana).

\section{2) Dainichi Nyorai}

Dainichi Nyorai (大日如来) adalah istilah untuk menyebut Sang Buddha Gautama atau Vairocana. Vairocana juga dilihat sebagai perwujudan konsep Buddha Sunnyatā. Dalam konsep tentang Lima Tathagata dari Buddhisme Mahayana dan Vajrayana, Vairocana berada di pusat dan dianggap sebagai Buddha Primordial.

Dalam Buddhisme Sino-Jepang, Vairocana atau Dainichi Nyorai secara bertahap digantikan sebagai objek penghormatan, sebagian besar karena meningkatnya popularitas Budha Tanah Suci (浄土 仏教), tetapi warisan Vairocana masih tetap berada di kuil Toudai-ji dengan patung perunggunya yang besar dan di Shingon Buddhisme, yang membawa pengaruh besar di kalangan umat Buddha Jepang. (https://en.wikipedia.org/wiki/Vairocana).

\section{3) Ohirumemuchi}

Istilah Oohirumemuchi (大日 靈 貴) merupakan istilah lain untuk Kami yaitu Amaterasu Omikami (天照大神) yang merupakan penguasa langit tinggi dan dewa matahari dalam mitologi Jepang, dianggap sebagai leluhur Kaisar Jepang saat ini dan dewa tertinggi Shinto .

(https://kotobank.jp/word/大日䨓貴-450724, https://zh.wikipedia.org/zh/天照大神).

\subsection{Skema aktansial}

Ditemukan tiga aktan utama yang mendominasi cerita dalam cerpen Kamigami no Bishou sebagai berikut. 
Izumi, Volume 7 No 2, 2018

e-ISSN: 2502-3535, p-ISSN: 2338-249X

Tersedia online di http://ejournal.undip.ac.id/index.php/izumi

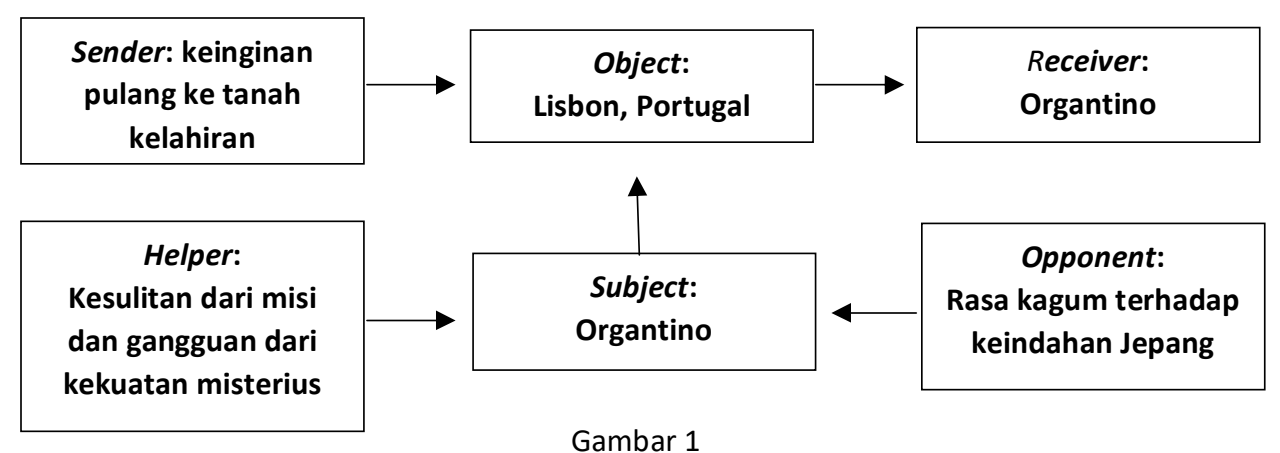

Gambar 1

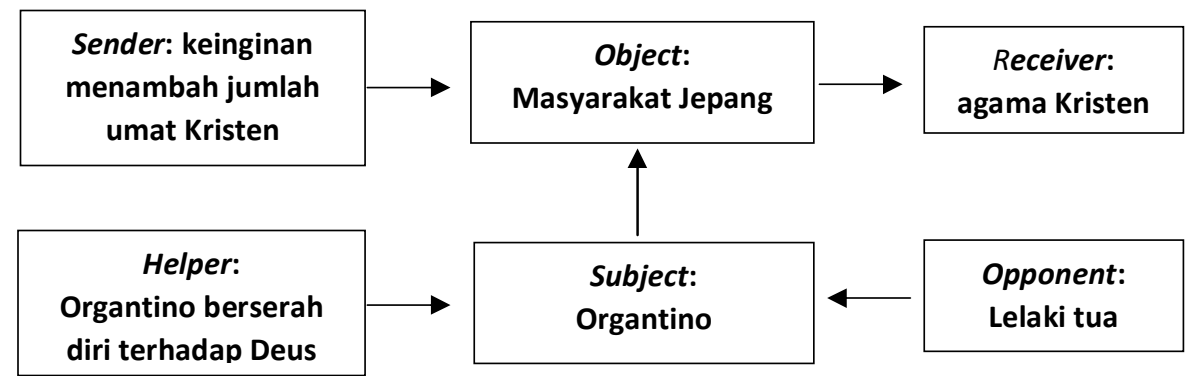

Gambar 2

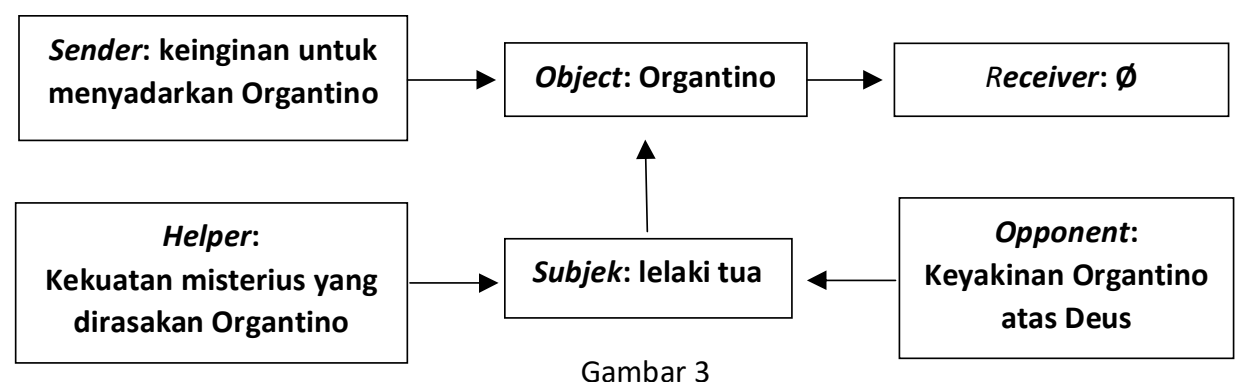

a). Aktan 1

Berdasarkan gambar 1, dapat dipahami bahwa keinginan kuat Organtino (subject) untuk pulang (sender) ke tempat kelahirannya di Lisbon, Portugal (object) membuat Organtino gelisah. Berikut kutipan yang menggambarkan keinginan Organtino untuk pulang ke negaranya.

リスポアの市へ帰りたい、この国を去り たいと思う事がある。これは懐郷の悲し みだけであろうか? いや、自分はリス ポアでなくとも、この国を去る事が出来 さえすれば、どんな土地へでも行きたい と思う。支那でも、沙室でも、印度でも、

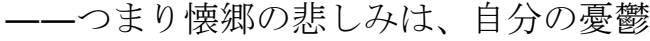
の全部ではない（神神の微笑）

$\mathrm{Aku}$ ingin pulang $\mathrm{ke}$ Lisbon, ingin meninggalkan negara ini dan kembali ke tanah kelahiranku. Apakah ini hanya karena nostalgia untuk tanah kelahiran saya? Tidak hanya Lisbon, tempat-tempat lain seperti Cina, Siam, dan India akan baik-baik saja, selama saya bisa meninggalkan negara ini. Jadi nostalgia bukan satu-satunya penyebab depresi saya.

Kegundahan Organtino untuk pulang ke negaranya diperkuat dengan kesulitan dari misi yang dirasakan Organtino untuk mengkristenkan orang Jepang dan ada 
Izumi, Volume 7 No 2, 2018

e-ISSN: 2502-3535, p-ISSN: 2338-249X

Tersedia online di http://ejournal.undip.ac.id/index.php/izumi

kekuatan misterius di Jepang yang mengganggu misinya tersebut (helper). Berikut kutipan yang mengindikasikan tersebut.

この国には山にも森にも、あるいは家々 の並んだ町にも、何か不思議な力が潜ん で居ります。そうしてそれが冥々の中に、 私の使命を妨げて居ります。さもなけれ ば私はこの頃のように、何の理由もない 憂冀の底へ、沈んでしまう筈はございま すまい。ではその力とは何であるか、そ れは私にはわかりません。（神神の微笑） Namun, sementara di tanah Jepang ini, saya telah mulai menyadari kesulitan dari misi saya. Beberapa kekuatan misterius bersembunyi di rumah-rumah, kota-kota, hutan, dan pegunungan di tanah ini. Dan kekuatan tak terlihat ini telah mengganggu pekerjaan saya di negeri ini. Kalau tidak, mengapa saya harus merasa sangat tertekan tanpa alasan? Saya masih tidak mengerti apa kekuatan ini.

Yang membuat Organtino tetap bertahan adalah kekagumannya terhadap Jepang yang memiliki pemandangan indah. Dalam skema di atas, hal ini menjadi opponent dari keinginannya untuk pulang ke Jepang.

\section{自分はただこの国から、一日も早く逃れ たい気がする。しかし——しかしこの国 の風景は美しい。（神神の微笑）}

Saya hanya ingin melarikan diri dari tanah ini secepat mungkin, tapi... tetap saja pemandangan negeri ini indah.

b) Aktan 2

Dari gambar ke-2 diketahui bahwa keinginan Organtino untuk memperbanyak pengikut Kristen (sender) yang membawanya untuk pergi meninggalkan kampung halamannya di Lisbon Portugal menuju Jepang. Tujuannnya adalah untuk mengkristenkan orang Jepang (object).

$$
\begin{aligned}
& \text { が、とにかくその力は、ちょうど地下の } \\
& \text { 泉のように、この国全体へ行き渡って居 }
\end{aligned}
$$

ります。まずこの力を破らなければ、お お、南無大慈大悲の泥烏須如来！ 邪宗 に惑溺した日本人は波羅葦増（天界）の 荘厳を拝する事も、永久にないかも存じ ません。（神神の微笑）

Tapi bagaimanapun kekuatannya menyebar ke seluruh negeri ini seperti air mancur di bawah tanah. Pertama-tama, jika Anda tidak mematahkan kekuatan ini, oh, Tuhanku, tidak mungkin mengirim orang Jepang yang sesat ini ke surga, selamanya.

Kutipan di atas adalah bagian dari doa Organtino yang memohon kekuatan kepada Deus untuk memperbanyak umat Kristen. Ajaran Kristen mempercayai adanya surga dan manusia akan masuk surga apabila mempercayai Deus. Oleh karena itu, Organtino memohon kepada Deus agar tujuannya tersebut tidak mendapat halangan dari kekuatan misterius yang dirasakannya.

Meskipun terdapat kesulitan dalam penyebaran misinya, tetapi Organtino tetap tabah karena dia berserah diri terhadap Tuhannya (helper). Dengan jumlah umat yang semakin banyak, maka agama Kristen (receiver) akan semakin berjaya. Tantangan Organtino datang dari seorang lelaki tua yang datang dan memberi tahu bahwa usaha Organtino untuk membuat Jepang benarbenar Kristen adalah usaha yang sia-sia karena Jepang memiliki pengalaman dalam menyerap ajaran pendatang dan mentransformasikannya sesuai dengan budaya dan kepercayaan asli Jepang. Kutipan berikut adalah perkataan lelaki tua kepada Organtino bahwa usahanya menyebarkan Kristen di Jepang adalah usaha yang sia-sia.

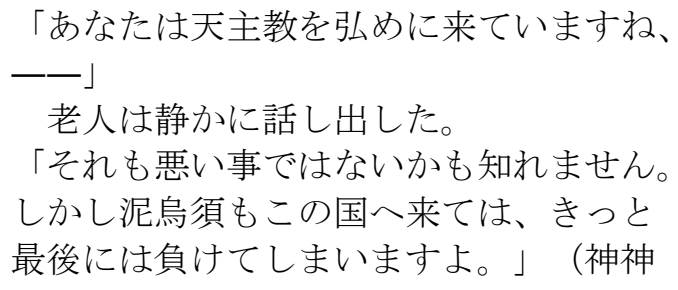


Izumi, Volume 7 No 2, 2018

e-ISSN: 2502-3535, p-ISSN: 2338-249X

Tersedia online di http://ejournal.undip.ac.id/index.php/izumi

の微笑）

"Jadi kamu datang ke negeri ini untuk menyebarkan ajaran Tuhanmu, kan?" Orang tua itu melanjutkan, "Itu mungkin bukan ide yang buruk, tetapi pada akhirnya, Tuhanmu akan kalah di negeri ini."

Meskipun begitu, Organtino tetap pada keyakinannya bahwa Tuhannya tidak akan kalah. Mendengar itu, lelaki tua tersebut berkata bahwa Organtino dan Tuhannya bukan satu-satunya yang pernah datang ke Jepang. Jauh sebelumnya, banyak paham yang masuk ke Jepang, tetapi hal itu tidak membuat Jepang menjadi berubah. Berikut kutipan yang berisi dialog antara Organtino dengan lelaki tua tersebut.

「泥烏須に勝つものはない筈です。」

「ところが実際はあるのです。まあ、御 聞きなさい。はるばるこの国へ渡って来 たのは、泥烏須ばかりではありません。 孔子、孟子、荘子、一一そのほか支那か らは哲人たちが、何人もこの国へ渡って 来ました。しかも当時はこの国が、まだ 生まれたばかりだったのです。支那の哲 人たちは道のほかにも、呉の国の絹だの 秦の国の玉だの、いろいろな物を持って 来ました。いや、そう云う宝よりも尊い、 霊妙な文字さえ持って来たのです。が、 支那はそのために、我々を征服出来たで しょうか。（神神の微笑）

"Tidak, tidak ada yang mengalahkan Tuhan kita," kata Organtino. "Tapi kenyataannya ada. Sekarang dengarkan aku baikbaik. Tuhanmu bukan satu-satunya yang datang ke negeri ini dari jauh. Banyak pemikir seperti Konfusius dan Mencius juga datang. Sejak saat negara ini masih muda, orang Cina membawa berbagai barang, termasuk sutra dan batu giok. " Mereka membawa sesuatu yang lebih penting, tulisan-tulisan Cina yang indah. Tetapi karena itu, apakah Cina telah menaklukkan negara ini?

「事によると泥烏須自身も、この国の土 人に変るでしょう。支那や印度も変った のです。西洋も変らなければなりません。
我々は木々の中にもいます。浅い水の流 れにもいます。薔薇の花を渡る風にもい ます。寺の壁に残る夕明りにもいます。 どこにでも、またいつでもいます。御気 をつけなさい。御気をつけなさい。 .........」（神神の微笑）

"Bahkan Deus dapat berubah menjadi dewa asli negeri ini, sama seperti orang-orang dari China dan India telah berubah. Baratpun juga pasti berubah. Kami (para dewa) berada di pepohonan, di sungai yang dangkal, di atas angin sepoi-sepoi di atas bunga mawar ini, dan dalam cahaya senja yang terpantul di dinding kuil. Kami di mana saja dan kapan saja. Jadi hati-hati.

\section{c) Aktan ke-3}

Dalam gambar ke-3 diketahui bahwa keinginan untuk menyadarkan Organtino akan kekuatan dewa-dewa Jepang (sender) membuat salah satu dewa Jepang dalam wujud lelaki tua menemui Organtino (object). Dialog terjadi antara lelaki tua tersebut dengan Organtino. Lelaki tua mengingatkan Organtino agar menghentikan usahanya untuk mengkristenkan bangsa Jepang. Lelaki tua itu memberi beberapa contoh kekuatan adaptasi Jepang atas pengaruh asing dalam mentransformasikan dan nenyesuaikanmya ke dalam karakter khas Jepang. Keyakinan Organtino atas Tuhannya (opponent) membuat Organtino sempat menjawab dan berdebat dengan lelaki tua. Lelaki tua tersebut berusaha meyakinkan Organtino bahwa ajaran Kristen dan Tuhannya tidak akan menang melawan para Dewa Jepang.

Dari ketiga aktan di atas dapat dilihat bahwa motivasi utama Organtino berada di Jepang adalah untuk mengkristenkan orang Jepang. Akibat merasa kesulitan dalam misinya, Organtino kemudian berkeinginan untuk pulang ke negaranya. Organtino merasa ada kekuatan yang misterius yang menghalangi misinya. Pada akhirnya Organtino mengetahui bahwa kekuatan misterius tersebut berasal dari kekuatan dewa-dewa Jepang. Salah satu dari dewa 
tersebut mewujud menjadi sosok lelaki tua dan memperingatkan Organtino bahwa usahanya tersebut akan sia-sia belaka.

\subsection{Tema}

Tema dalam cerpen ini adalah tema nontradisional karena jalinan ceritanya tidak mengungkapkan sesuatu yang menjadi umumnya cerita, misalnya tentang kebenaran yang menang melawan kejahatan, atau kesabaran akhirnya akan membuahkan hasilnya. Cerita dalam Kamigami no Bishou dapat ditafsirkan sebagai resistensi Jepang terhadap pengaruh dari luar, khususnya Barat. Resistensi atau perlawanan tersebut tidak dalam arti harus menang atau kalah, akan tetapi pengaruh asing tersebut ditransformasikan ke bentuk baru yang sesuai dengan tradisi dan budaya Jepang. Gambaran mengenai tema tersebut diantaranya terekonstruksi melalui dialog antara Organtino dan tokoh lelaki tua. Organtino memiliki keinginan untuk menyebarkan agama Kristen di Jepang, sedangkan lelaki tua memperingatkan Organtino bahwa usahanya tersebut akan sia-sia belaka. Lelaki tua tersebut menjelaskan bahwa bangsa Jepang memiliki kemampuan untuk mentransformasikan segala pengaruh asing yang masuk ke Jepang dan mengubahnya ke dalam bentuk yang baru yang khas Jepang.

Judul cerpen yaitu Kamigami no Bishou juga memperkuat tema tersebut. "Kamigami" berarti dewa-dewa, sedangkan "Bishou" berarti senyuman. Judul tersebut dapat ditafsirkan bahwa para dewa Jepang tersenyum melihat kebingungan Organtino yang merasa kesulitan untuk mengembangkan ajaran agamanya di Jepang. Selain itu dapat ditafsirkan pula bahwa meskipun pengaruh budaya asing deras masuk ke Jepang, akan tetapi dewa-dewa Jepang sebagai penjaga budaya Jepang tetap tersenyum mempersilakan semua pengaruh tersebut masuk ke Jepang karena dengan penjagaannya akan membuat semua pengaruh asing tersebut disesuaikan dengan tradisi dan budaya Jepang.

\subsection{Rekonstruksi benturan budaya}

Salah satu arti dari rekonstruksi adalah penyusunan (penggambaran) kembali; sedangkan merekonstruksi adalah melakukan rekonstruksi. Karya sastra adalah mimesis atau tiruan dari kehidupan dan masyarakat. Oleh karena itu, cerpen Kamigami no Bishou dapat ditafsirkan sebagai penggambaran kembali mengenai kehidupan manusia yang disampaikan pengarang dalam karyanya.

Budaya merupakan satu cara atau jalan hidup masyarakat atau bangsa yang diturunkan dari satu generasi ke generasi berikutnya. Sedangkan kebudayaan menurut Koentjaraningrat merupakan keseluruhan suatu sistem gagasan, tindakan, serta hasil karya manusia dalam kehidupan. Ada tujuh unsur kebudayaan yaitu bahasa, sistem pengetahuan, sistem kemasyarakatan, sistem peralatan hidup dan teknologi, mata pencaharian, religi, dan kesenian.

Dalam sejarah, bangsa Jepang telah dimasuki berbagai pengaruh dari luar. Akan tetapi, tradisi dan budaya yang unik bangsa Jepang tidak pudar atau punah. Justru, pengaruh yang datang dari luar berhasil dimanfaatkan bangsa Jepang dalam memperkaya tradisinya. Bangsa Jepang tidak hanya begitu saja menerima pengaruh dari luar, tetapi dengan kekuatan inovasinya mentransformasikannya ke dalam bentuk yang lebih diterima tradisinya.

Dalam cerpen Kamigami no Bishou, rekonstruksi benturan budaya yang ingin disampaikan oleh Akutagawa tergambar dalam binary opposition atau oposisi biner antaratokoh Organtino versus tokoh lelaki tua. Suspense cerita juga terjadi ketika dialog antara Organtino versus lelaki tua. Organtino menyebutkan bahwa dia melaksanakan misinya karena ingin mengabdikan dirinya kepada Deus. Berikut kutipan yang menunjukkan tekad Organtino tentang pengabdian tulusnya kepada Deus, Tuhannya.

\section{「南無大慈大悲の泥烏須如来！ 私はリ スポアを船出した時から、一命はあなた}


Izumi, Volume 7 No 2, 2018

e-ISSN: 2502-3535, p-ISSN: 2338-249X

Tersedia online di http://ejournal.undip.ac.id/index.php/izumi

に奉って居ります。ですから、どんな難

儀に遇っても、十字架の御威光を輝かせ

るためには、一歩も怯まずに進んで参り

ました。（神神の微笑）

"Oh, Tuhan yang berbelas kasih, sejak saya meninggalkan pelabuhan Lisbon, saya telah memberikan hidup saya kepada Anda. Jadi tidak peduli betapa aku menderita, aku tidak pernah menyerah menerangi salibmu.

Sedangkan, tokoh lelaki tua muncul setelah Organtino belum selesai terkejut menyaksikan adegan bacchanalia ${ }^{3}$ yang dianggapnya sebagai halusinasi. Lelaki tua tersebut mengaku sebagai salah satu roh dari Jepang.

$$
\begin{aligned}
& \text { 「誰だ、お前は?」 } \\
& \text { 不意を打たれたオルガンティノは、思 } \\
& \text { わずこへ立ち止まった。 } \\
& \text { 「私は、一一誰でもかまいません。この } \\
& \text { 国の霊の一人です。」 } \\
& \text { 老人は微笑を浮べながら、親切そうに } \\
& \text { 返事をした。（神神の微笑） }
\end{aligned}
$$

"Siapa kamu?" Tanya Organtino yang terkejut . "Saya? Tidak penting siapa aku. Saya adalah salah satu roh dari negeri ini”, jawab lelaki tua itu sambil tersenyum.

Sejak pertemuan antara Organtino dan lelaki tua di atas, cerita berpusat pada dialog antara keduanya. Lelaki tua tersebut berusaha meyakinkan Organtino bahwa usahanya untuk menyebarkan Kristen di Jepang akan sia-sia dan Deus tidak akan menang melawan dewa-dewa Jepang seperti yang terlihat pada kutipan berikut.

\footnotetext{
3 Bacchanalia adalah festival Romawi Bacchus, dewa anggur Yunani-Romawi. Bacchanalia diadakan dengan kerahasiaan yang ketat, dan para inisiat terikat untuk menjaga kerahasiaan; apa yang sedikit diketahui tentang kultus dan ritusnya berasal dari sastra Yunani dan Romawi, drama, patung dan lukisan.Dalam penggunaan modern, bacchanalia dapat berarti pesta pora tanpa hambatan atau mabuk. Bacchanal dalam seni menggambarkan sekelompok kecil orang yang bersuka ria, sering termasuk satyrs dan mungkin Bacchus atau Silenus, biasanya dalam latar lanskap. Subjek itu populer dari masa Renaissance dan biasanya termasuk sebagian besar ketelanjangan di antara tokoh-tokoh itu.(Wikipedia.org/wiki/Bacchanalia)
}

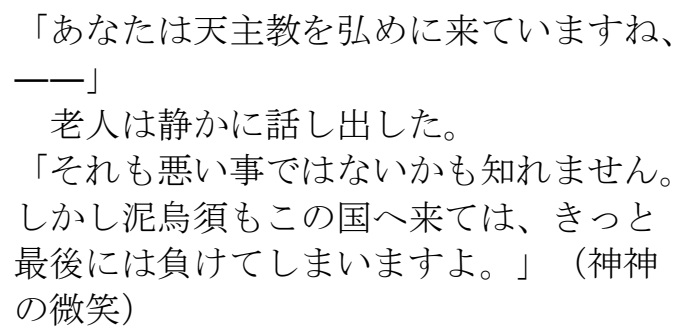

"Jadi kamu datang ke negeri ini untuk menyebarkan ajaran Tuhanmu, kan?" Orang tua itu melanjutkan, "Itu mungkin bukan ide yang buruk, tetapi pada akhirnya, Deus (Tuhanmu) akan kalah di negeri ini."

Deus dan ajarannya dalam cerpen ini ditempatkan sama nasibnya dengan berbagai ajaran impor seperti ajaran Buddha, Konfucius, maupun Mencius yang masuk dan berkembang di Jepang, tetapi ajaranajaran tersebut diadopsi sedemikian rupa tanpa mengubah warna asli dari tradisi dan kepercayaan Jepang. Dengan kata lain, lelaki tua tersebut mengatakan bahwa walaupun ajaran Kristen disebarkan di Jepang, tetapi tidak akan menaklukkan tradisi dan kepercayaan asli bangsa Jepang. Berikut kutipan-kutipan yang menggambarkan hal tersebut.

$$
\begin{aligned}
& \text { 「泥烏須に勝つものはない筈です。」 } \\
& \text { 「ところが実際はあるのです。まあ、御 } \\
& \text { 聞きなさい。はるばるこの国へ渡って来 }
\end{aligned}
$$

"Tidak, tidak ada yang mengalahkan Tuhan kita," kata Organtino. "Tapi kenyataannya ada. Sekarang dengarkan aku baikbaik. Tuhanmu bukan satu-satunya yang datang ke negeri ini dari jauh. Banyak pemikir seperti Konfusius dan Mencius juga datang. Sejak saat negara ini masih muda, 
orang Cina membawa berbagai barang, termasuk sutra dan batu giok. " Mereka membawa sesuatu yang lebih penting, tulisan-tulisan Cina yang indah. Tetapi karena itu, apakah Cina telah menaklukkan negara ini?

「仏陀の運命も同様です。が、こんな事 を一々御話しするのは、御退屈を増すだ けかも知れません。ただ気をつけて頂き たいのは、本地垂跡の教の事です。あの 教はこの国の土人に、大日は大日如来と 同じものだと思わせました。これは大日 孁貴の勝でしょうか? それとも大日如 来の勝でしょうか? 仮りに現在この国 の土人に、大日孁貴は知らないにしても、 大日如来は知っているものが、大勢ある として御覧なさい。それでも彼等の夢に 見える、大日如来の姿の中には、印度仏 の面影よりも、大日靈貴が窺われはしな いでしょうか? （神神の微笑）

"Nasib Sang Buddha, Sidharta, tidak berbeda dari para pemikir lain dari negeri asing. Anda mungkin bosan dengan pembicaraan saya. Tapi hati-hati tentang hal-hal di tanah ini, terutama ajaran honji suijaku yang mengajarkan penduduk asli bahwa Dainichi (Buddha) adalah sama dengan Dainichi Nyorai/Ohirume. Apakah ini kemenangan Ohirume atau Buddha? Anggaplah banyak penduduk asli negeri ini akrab dengan Buddha. Namun, bukankah mungkin di dalam sosok Dainichi/Buddha yang muncul dalam mimpi mereka, dibanding itu adalah Buddha dari India, lebih mungkin itu adalah penjelmaan Ohirume?"

Dalam kutipan di atas, lelaki tua ingin menjelaskan bahwa meskipun ajaran Buddha dengan sosok Sang Siddharta Gautama diterima oleh penduduk Jepang, akan tetapi Sang Buddha dianggap sebagai manifestasi dari Ohirume. Terdapat istilah honji suijaku atau honchi suijaku (本地 垂 迹) yang dalam terminologi agama Jepang mengacu pada teori yang diterima secara luas hingga periode Meiji dimana Buddha memilih untuk muncul di Jepang sebagai
Kami atau dewa Jepang agar lebih mudah membuat orang Jepang masuk atau mempercayai Buddha. Teori ini menyatakan bahwa beberapa dewa Jepang (tetapi tidak semua) adalah manifestasi (垂 迹/jejak) dari Buddha (本地/tanah asli). Kedua entitas membentuk keseluruhan yang disebut gongen dan secara teori harus memiliki kedudukan yang sama, tetapi ini tidak selalu terjadi. Pada awal periode Nara, misalnya, honji / Buddha dianggap lebih penting dan hanya kemudian di akhir periode tersebut keduanya dianggap menjadi sama pentingnya. Selama periode Kamakura akhir, bahkan diusulkan bahwa kami adalah dewa asli dan para buddha adalah manifestasi mereka. Teori ini tidak pernah sistematis tetapi tetap sangat meresap dan sangat berpengaruh.

Meskipun lelaki tua mengatakan bahwa Deus tidak akan menang di Jepang, Organtino mengatakan bahwa misinya mungkin akan berhasil dengan bukti beberapa samurai telah bergabung ke dalam Kristen. Lelaki tua tersebut kemudian menjelaskan bahwa kekuatannya bukan bersifat menghancurkan tetapi kekuatan untuk mentransformasi atau mengubah. Berikut kutipan dialog keduanya.

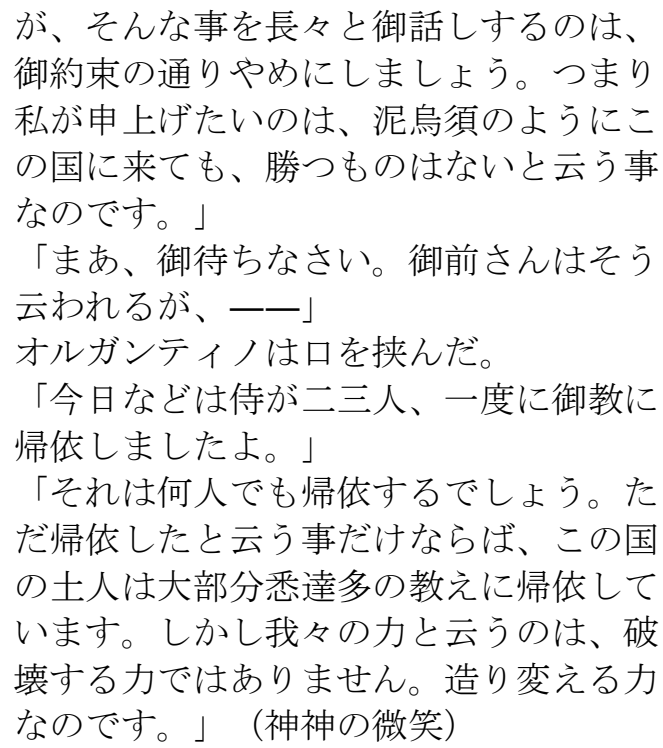

Tapi mari kita berhenti membicarakan halhal seperti itu sesuai yang kamu janjikan. 
Izumi, Volume 7 No 2, 2018

e-ISSN: 2502-3535, p-ISSN: 2338-249X

Tersedia online di http://ejournal.undip.ac.id/index.php/izumi

Dengan kata lain, yang ingin saya katakan adalah jika datang ke negara ini seperti Tuhan Deus Anda, tidak akan menang." "Anda mungkin mengatakan demikian, tetapi ada dua tiga samurai bergabung dengan jemaat kami hari ini, "sela Organtino. "Tentunya, jumlah dari mereka dapat dikonversi ke ajaran Anda, sama seperti mayoritas penduduk asli telah terpengaruh oleh ajaran Buddha. Tapi itu bukan masalah di sini. Yang saya bicarakan adalah kekuatan mereka, kemampuan mentransformasikan dan menyesuaikan [apa yang telah diimpor]. Itu bukan kekuatan penghancuran.

Walaupun begitu, Organtino tetap berkeras bahwa Deus-lah yang akan menang. Organtino memberi contoh tentang Yunani yang meski memiliki dewa $\mathrm{Pan}^{4}$, tetapi Kristen berkembang pesat di Yunani seperti yang tergambar dalam dialog berikut.

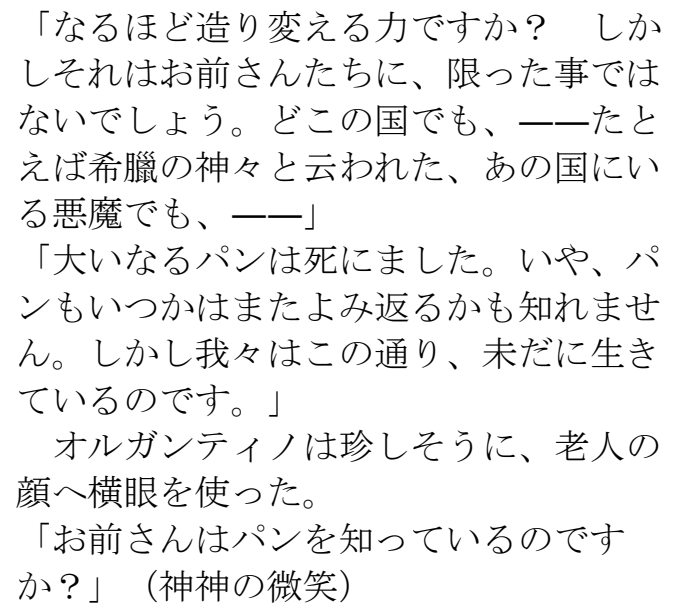

"Memang, kekuatan transformasi. Namun, itu belum tentu unik untuk tanah ini. Di negara lain ... berbagai dewa Yunani dan iblis tanah lain. . "Kata Organtino . "Oh, maksudmu Pan yang mati. Yah, dia mungkin akan hidup kembali suatu hari nanti . Tapi kami masih hidup di negeri ini. "Organtino ingin tahu memberi pandangan kepada orang tua itu, dan bertanya," Apakah Anda tahu sesuatu tentang Pan?"

Mendengar kesangsian Organtino, lelaki tua tersebut bercerita pengalaman lain

${ }^{4}$ Pan adalah dewa Yunani berwujud separuh manusia, separuh kambing
Jepang dalam mentransformasikan yang berasal dari luar menjadi sesuatu yang baru, yaitu kisah mengenai Ulysess yang ditransformasikan menjadi Yuriwaka. ${ }^{5}$

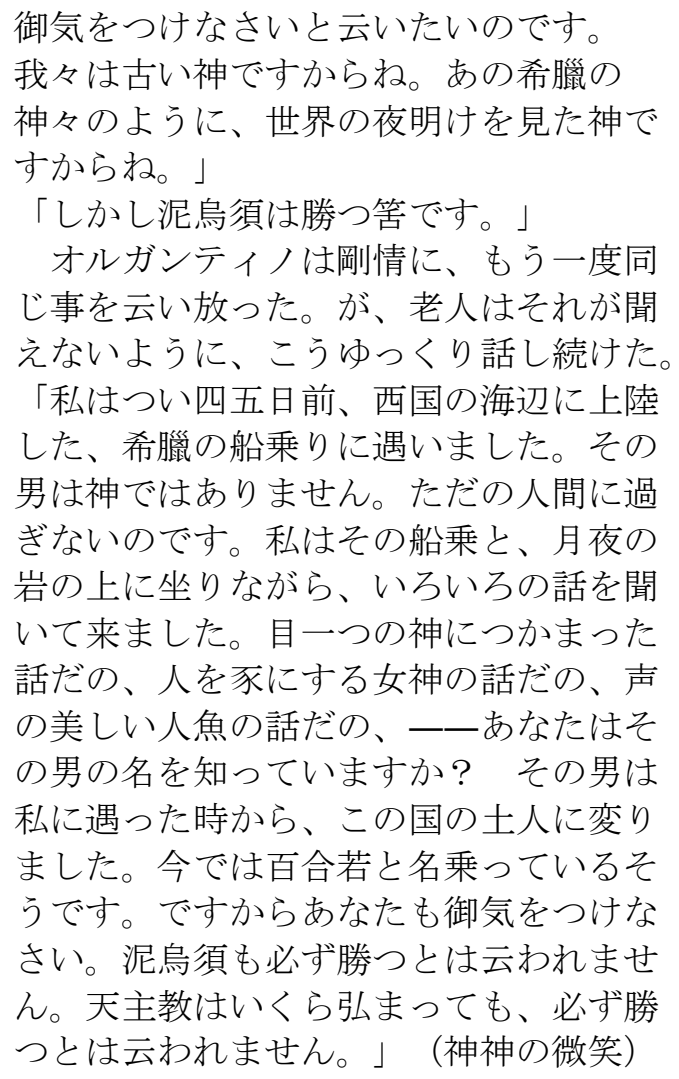

Anda harus lebih berhati-hati. Kami adalah dewa tua, setua orang Yunani yang melihat fajar dunia ini. "' Tapi Deus (Tuhan) akan menang, "ulang Organtino dengan tegas. Mengabaikannya, lelaki tua itu perlahan melanjutkan, "Beberapa hari yang lalu, saya pergi menemui seorang

\footnotetext{
${ }^{5}$ Yuriwaka, pahlawan Jepang yang terkenal karena busur besinya yang sangat besar, menang sebagai jenderal melawan pasukan Mongolia, tetapi ditinggalkan di sebuah pulau oleh seorang bawahan pengkhianat (Beppu). Elang Yuriwaka (Midori-maru) mengembalikan surat kepada istrinya, yang berdoa ke kuil, dan melalui intervensi ilahi, Yuriwaka kembali ke provinsinya. Dia menahan identitasnya sampai saat yang tepat untuk membuktikan kehebatannya di busur besi, dan membalas dendam pada pengkhianat.Dongeng ini dianggap sebagai terjemahan Jepang dari epik Yunani Ulysses. Tetapi sejumlah komentator telah menolak asumsi ini, tidak menemukan kisah yang meyakinkan tentang bagaimana kisah itu bisa ditularkan. Penjelasan umum adalah bahwa para misionaris Kristen memperkenalkan kisah ini. Referensi tertua yang diketahui adalah dari 1514, memberikan nama-nama pahlawan dan elang. Dulunya yang tertua dianggap sebagai catatan Yuriwaka yang diriwayatkan pada Februari 1551, beberapa saat setelah kontak misionaris Eropa pertama dengan Jepang.
} 
Izumi, Volume 7 No 2, 2018

e-ISSN: 2502-3535, p-ISSN: 2338-249X

Tersedia online di http://ejournal.undip.ac.id/index.php/izumi

pelaut Yunani yang mendarat di pantai sebuah provinsi barat di negeri ini. Dia bukan dewa, hanya manusia. Duduk di atas batu bersamanya di malam yang diterangi cahaya bulan, saya mendengar dia menceritakan semua jenis cerita, termasuk satu tentang dewa bermata satu, seorang dewi yang mengubah manusia menjadi babi, dan putri duyung dengan suara yang indah. Apakah Anda tahu nama pelautnya? Begitu dia bertemu saya, dia berubah menjadi penduduk asli negeri ini. Dia sekarang

disebut Yuriwaka [Ulysses]. Jadi, Anda harus berhati-hati. Anda tidak bisa mengatakan bahwa Deus Anda akan menang. Ajaran Katolik Anda tidak akan selalu menang, tidak peduli seberapa banyak mereka menyebar di negara ini.

Dari kutipan di atas, dapat dipahami bahwa tokoh lelaki tua ingin menganalogikan pengalaman bangsa Jepang dalam mentransformasi Ulysses menjadi Yuriwaka dengan Deus yang tidak akan menang meskipun banyak orang Jepang yang memeluk Kristen. Para dewa Jepang pasti akan berhasil mentransformasikan Deus ke dalam sesuatu yang khas bangsa Jepang.

Dari beberapa pemaparan di atas, dapat diketahui bahwa dialog antara Organtino dan lelaki tua berpusat pada debat argumen mengenai siapakah yang akan menang antara Deus versus Ohirume. Oleh karena itu, dapat dikatakan bahwa Deus versus Ohirume juga merupakan binary opposition yang penting dalam cerpen ini, karena dari hal yang dipertentangkan tersebut dapat ditarik pesan yang ingin disampaikan oleh Akutagawa Ryuunosuke sebagai pengarang cerpen ini. Pesan tersebut adalah bahwa bagaimanapun pengaruh asing masuk dan berkembang di Jepang, pengaruh asing tersebut tidak akan bisa mengalahkan tradisi dan budaya Bangsa Jepang.

\section{Simpulan}

Rekonstruksi benturan budaya dalam cerpen Kamigami no Bishou dipaparkan oleh Akutagawa dalam percakapan antara tokoh Organtino dengan tokoh lelaki tua, khususnya penjelasan lelaki tua ketika memaparkan pengalaman bangsa Jepang dalam menghadapi pengaruh asing yang masuk ke Jepang. Bangsa Barat datang ke negara-negara Timur, termasuk ke Jepang, dengan semboyan Gold, Gospel, dan Glory. Semboyan gospel berarti bahwa kedatangan bangsa Barat juga bertujuan untuk menyebarkan ajaran Kristen ke negara yang didatanginya. Sesuai dengan semboyan tersebut, Organtino membawa ajaran Kristen dan menyebarkannya kepada penduduk Jepang. Organtino menginginkan kemenangan Deus terhadap kekuatan misterius di Jepang yang dirasakannya. Tokoh lelaki tua yang mengaku sebagai salah satu roh tertua Jepang datang menemui Organtino untuk mengingatkan bahwa ajaran Kristen tidak akan menang sebagaimana pengaruh asing sebelumnya yang pernah masuk ke Jepang. Sebaliknya, masuknya budaya asing bagi bangsa Jepang tidak diartikan harus ada yang menang dan ada yang kalah. Pengaruh asing tersebut akan ditransformasikan ke bentuk baru yang sesuai dengan budaya dan tradisi Jepang.

Melalui paparan tokoh lelaki tua, Akutagawa menyiratkan kekuatan transformasi bangsa Jepang yang terlihat jauh sebelum ajaran Kristen datang ke Jepang. Ajaran Buddha datang ke Jepang dan menarik minat rakyat Jepang untuk menganutnya. Akan tetapi, ajaran Buddha yang masuk ditransformasikan ke dalam bentuk baru yang sesuai dengan kepercayaan bangsa Jepang sebelumnya. Bagi bangsa Jepang, Shiddarta Buddha adalah manifestasi dari Ohirume, dewa tertinggi dalam kepercayaan Shinto. Begitu pula pengaruh asing lain seperti ajaran Konfucius, Mensius, Taoisme, dongeng Ulysess, dan aksara Kanji Jepang. Bagi Akutagawa, pengaruh budaya Barat termasuk di dalamnya adalah ajaran Kristen 
Izumi, Volume 7 No 2, 2018

e-ISSN: 2502-3535, p-ISSN: 2338-249X

Tersedia online di http://ejournal.undip.ac.id/index.php/izumi

sama dengan pengaruh asing lainnya yang sebelumnya masuk ke Jepang. Kesimpulannya, melalui dialog yang berpusat pada Deus versus Ohirume yang dilakukan oleh tokoh Organtino dan tokoh lelaki tua, secara tidak langsung Akutagawa

\section{DAFTAR PUSTAKA}

Chandler, D. (2005). Semiotics: The Basics.pdf. Routledge. Retrieved from biblioteca/algorithms/Semiotics/sem0a. html

Cieslik, H. (2005). Early Missionaries in Japan 6 Soldo Organtino: The Architect of the Japanese Mission. Retrieved November 14, 2018, from https:/www.researchgate.net/publicatio n/242429665_Early_Missionaries_in_J apan_6_Soldo_Organtino_The_Archite ct_of_the_Japanese_Mission

Essertier, J. (2014). Akutagawa Ryunosuke and Harmonious Multiplicity in "The Faint Smiles of the Gods" (Kamigami no bisho, 1922). Nagoya Institute of Technology Repository. Retrieved from https://nitech.repo.nii.ac.jp/?action=rep ository_action_common_download\&ite 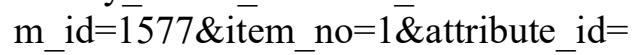 $12 \&$ file_no $=1$

Gessel, V. C. (2018). Endô Shûsaku : His Position(s) in Postwar Japanese Literature Author ( s ): Van C. Gessel Source: The Journal of the Association ingin menyampaikan pesan bahwa tradisi dan budaya Jepang tidak akan hancur karena pengaruh dari budaya asing yang masuk.

of Teachers of Japanese, Vol . 27 , No . 1 ( Apr ., 1993 ), Published by :

American Association of Teachers of Japanese, 27(1), 67-74. Retrieved from https://www.jstor.org/stable/489126

Karatani, K., \& Lippit, S. M. (1991). The Discursive Space of Modern Japan. Boundary, 2.

Lippit, S. M. (1999). The Disintegrating Machinery of the Modern: Akutagawa Ryunosuke's Late Writings. The Journal of Asian Studies, 58(1), 27-50. https://doi.org/10.2307/2658388

Ryuunosuke, Akutagawa. Kamigami no Bishou. Diunduh pada 26 Juli 2018 dari https://www.aozora.gr.jp/cards/000879/ files/68_15177.html

https://en.wikipedia.org/wiki/Vairocana https://kotobank.jp/word/大日孁貴-450724 https://ja.wikipedia.org/wiki/神神の微笑 https://en.wikipedia.org/wiki/Bacchanalia https://id.wikipedia.org/wiki/Sinkretisme 